\title{
Use of a guideline based questionnaire to audit hospital care of acute asthma
}

\author{
Derek Bell, Amanda Jane Layton, John Gabbay
}

\begin{abstract}
Objectives - To design an audit questionnaire and pilot its use by an audit assistant to monitor inpatient management of acute asthma and to compare the care given by chest physicians and general physicians.
\end{abstract}

Design-Retrospective review by a chest physician and audit assistant of a random sample of 76 case records of patients by a criterion based questionnaire developed from hospital guidelines on management of acute asthma.

Setting-One district general hospital.

Patients -76 adult patients with acute asthma: 38 admitted with a relevant primary diagnosis between April 1988 and March 1989 and a further 38 admitted through the accident and emergency department between April 1989 and March 1990.

Main outcome measures-Conformity with recognised standards for assessment and management of acute asthma before and after the audit and by chest physicians and general physicians.

Results-Age and sex did not differ significantly between the different groups of patients. Overall, deviations from the guidelines occurred in recording measures of severity of asthma, emergency treatment with $\beta_{2}$ agonists $(60 / 76,79 \%)$ and steroids $(43 / 76,57 \%)$, and prescription of antibiotics in accordance with at least one criterion of the guidelines $(29 / 45,64 \%)$. Chest physicians were more rigorous than general physicians in recording severity measures, especially serum potassium concentration $\left(\chi^{2}=3 \cdot 6, d f=1, p=0.06\right)$, emergency steroid treatment within the correct period $\left(\chi^{2}=3.9\right.$, $\mathbf{d f}=1, \mathbf{p}=0.05$ ), and referral for follow up at an outpatient chest clinic. Recording of arterial blood gas tensions improved significantly between the 1988-9 and 1989-90 samples $\left(\chi^{2}=7 \cdot 0, \mathrm{df}=1, \mathrm{p}=0 \cdot 08\right)$.

Conclusions - The questionnaire proved easy to use for both doctor and audit assistant. The audit improved few standards of care and emphasises the need for further reinforcement and feedback.

Central Middlesex Hospital, London NW10 7NS

Derek Bell, MD, senior registrar in thoracic medicine

Health Care Development Unit, Academic Department of Public Health, St Mary's Hospital Medical School, The Bungalow, Central Middlesex Hospital, London NW10 7NS Amanda Jane Layton, BA, audit research nurse

John Gabbay, MFPHM, senior lecturer in public health medicine

Correspondence to: Dr J Gabbay.

\section{Introduction}

As medical audit becomes more widespread in the United Kingdom physicians are recognising the difficulties of agreeing defined and measurable standards against which an audit assistant might monitor the care of patients. One approach is to agree guidelines for managing particular conditions and use them to develop a questionnaire against which to assess treatment. As part of our audit programme at the Central Middlesex Hospital,' we have found it helpful to review just three or four records of patients with a given condition, and use that discussion as the springboard for developing local guidelines based not only on the literature but also on the aspects of care that seem locally to need improvement most. We then develop a questionnaire that is used to review a larger series of patients with that condition.

Asthma was one of the first topics we chose because it is a disease with an unarguably high morbidity and mortality in Britain, ${ }^{2}$ for which the local standardised mortality ratios were above average, ${ }^{3}$ and whose care is widely unsatisfactory. ${ }^{4-7}$ Patients commonly do not appreciate the severity of their acute asthmatic attack, ${ }^{4}$ but doctors may also not assess patients fully, ${ }^{5}$ may fail to treat rapidly and aggressively with steroids and bronchodilators, ${ }^{6}$ and may be reluctant to refer patients to chest physicians. ${ }^{7}$ The audit questionnaire we developed therefore focused on these areas and was consistent with the guidelines later produced by the British Thoracic Society. ${ }^{8}$

Our audit of asthma had the following objectives: $(a)$ to develop a questionnaire based on guidelines to monitor the assessment and management of inpatients with acute asthma and to identify the scope for improvement; $(b)$ to assess the differences between the chest and general physicians; $(c)$ to assess whether the general introduction of audit in March 1989 improved clinical care; and $(d)$ to pilot the use of the questionnaire with an audit assistant. We report some of the difficulties we encountered and discuss the findings as an example of how such audit might highlight the local features of clinical care that require improvement.

\section{Methods}

The questionnaire was developed in collaboration with the local consultant thoracic physicians and covered the initial clinical assessment and management, ward assessment and management, and subsequent follow up. Examples of how we derived questions from the guidelines are given in the box. We added two simple outcome measures not included in the guidelines: whether the patient was readmitted for asthma within three months and whether they died while in hospital.

From a population of about 400 adults aged 16 and over who were admitted with acute asthma during two years we audited the records of 76 inpatients, which would allow us to estimate reliably events with a prevalence as low as $5 \%$. Patients were admitted to the care of a thoracic or medical firm depending only on which firm was on call at the time. Thirty eight case records were sampled systematically, using a random starting point, for patients noted in the district information system as having been admitted with a relevant primary diagnosis (ICD (ninth revision) codes 493.0, 493.1, and 493.9) from April 1988 to March 1989, which were the 12 months before audit began in the hospital. With the same method the records of another 38 patients admitted between April 1989 and March 1990 were sampled from the records of the accident and emergency department, where nearly all patients with acute asthma are admitted. We were obliged to use the different sampling frames because the data information system was not sufficiently up to date for the second period of sampling and because the casualty computer had not been installed in 1988 .

We included all patients with acute asthma diagnosed during their admission who showed variable airways obstruction.

The reliability of the auditors was tested by comparing independently scored audits of the first and last 10 sets of records carried out by two of us, a thoracic 
Examples of statements from guidelines on management of asthma and questions derived from them

\section{Guidelines}

Example I

Immediate treatment:

Nebulised salbutamol $2 \cdot 5-5 \mathrm{mg}$

Nebulised ipratropium $500 \mu \mathrm{g}$

Intravenous hydrocortisone $200 \mathrm{mg}$

\section{Example 2}

Antibiotics overused-use only when fever, infected sputum, or consolidation on $x$ ray is present

\section{Example 3}

Assessment:

Should note indicators of severity such as: Inability to speak sentences

Low peak flow $(<100 \mathrm{l} / \mathrm{min})$. Always Example 4 measure and record peak flow

Take advice from respiratory firm before discharge and arrange follow up at chest outpatient clinic
Common faults of ward management:

\section{Audit question examples}

Were the drugs below given within 1 hour of arrival?

(a) Nebulised $\beta_{2}$ agonist

(b) Nebulised ipratropium prednisolone

(d) Theophylline or aminophylline

Were antibiotics prescribed during admission?

Did patient have:

(a) A temperature $>37 \cdot 5^{\circ} \mathrm{C}$ ?

(b) Clinically infected sputum? sputum?

(d) $x$ Ray consolidation?

On admission did patient's breathlessness prevent him or her speaking full sentences?

Was peak flow recorded?

If yes, please record rate

Was a follow up appointment made for this patient in the "chest clinic" on discharge? (c) Intravenous hydrocortisone or oral

(c) Microbiological evidence of infected

$\begin{array}{ccc}\text { Yes } & \text { No } & \begin{array}{c}\text { Not } \\ \text { sure }\end{array} \\ 1 & 2 & 3 \\ 1 & 2 & 3 \\ 1 & 2 & 3 \\ 1 & 2 & 3 \\ 1 & 2 & 3 \\ 1 & 2 & 3 \\ 1 & 2 & 3 \\ 1 & 2 & 3 \\ 1 & 2 & 3\end{array}$

physician (DB) and an audit research nurse (AJL), who each audited half of the remaining 56 notes. We used the $\chi^{2}$ test for comparison between the chest physicians and the general physicians and between the two time periods and $x$ analysis for comparing reliability between the auditors.

\section{Results}

To reach our intended sample size we were obliged to re-sample because of unavailability of records and because about a quarter of those retrieved through both systems were incorrectly coded as asthma, including, for example, patients admitted with epistaxis or full term delivery. Furthermore, four sets of records that fitted our diagnostic criteria could not be audited because vital documents such as the drug chart were missing.

The age group of the sample was 17-77 (median 32) years; there were 34 men and 42 women. There were no significant differences in age and sex of the patients between the two time periods or between the 34 patients seen by the thoracic physicians and the 42 seen by the general physicians. There were no deaths in hospital, and only one patient was admitted to the intensive therapy unit; eight patients were readmitted for asthma within three months, of whom two had discharged themselves. The mean length of stay was five days, median four days (range 0 to 19 days).

The audit assistant took a mean of 15 minutes to audit the records and the physician 13 minutes. Among the 20 case records reviewed by both there was significant agreement $(\geqslant 70 \%, x 0.5 ; \mathrm{p}<0.01)$ in 19 of the 24 items of information recorded, with $95 \%$ agreement achieved in 14 out of the 19 items. There was $75 \%$ agreement or more in eight out of 10 items for which $x$ analysis was not appropriate. On review the disagreements were not important and could easily be resolved by further discussion or training or by amending the phrasing of the questions. In general there was greater discrepancy for deduced information as opposed to directly recorded information. Questions whose design led to unreliable answers (for example, interpretations about the patient's tiredness or anxiety) were excluded from the analysis.

Table I shows the recordings of measures of severity of asthma and of serum potassium concentration. Chest physicians tended to record measures of severity more commonly than general physicians, with the greatest difference being in recording of serum potassium concentration $\left(\chi^{2}=3 \cdot 6, \mathrm{df}=1, \mathrm{p}=0 \cdot 06\right.$; table $\left.\mathrm{I}\right)$. Apart from a significant improvement in the recording of arterial blood gas tensions, $\left(\chi^{2}=7 \cdot 0, \mathrm{df}=1, \mathrm{p}=0 \cdot 008\right)$ and an improvement from $55 \%$ to $68 \%$ in the recording of "inability to speak sentences," there was little difference between the 1988-9 and the 1989-90 samples.

Table II shows the degree of adherence to the guidelines for emergency treatment, which we took as

TABLE I-Recording of measures of severity of asthma and serum potassium concentration by chest physicians and general physicians in 76 patients

\begin{tabular}{llcc}
\hline & \multicolumn{3}{c}{ No (\%) of case records } \\
\cline { 2 - 4 } & $\begin{array}{c}\text { Overall } \\
(\mathbf{n}=76)\end{array}$ & $\begin{array}{c}\text { Chest } \\
\text { physicians } \\
(\mathbf{n}=34)\end{array}$ & $\begin{array}{c}\text { General } \\
\text { physicians } \\
(\mathbf{n}=42)\end{array}$ \\
\hline Measures & 76 & 34 & 42 \\
Pulse rate & $74(97)$ & 34 & $40(95)$ \\
Peak flow & $47(62)$ & $25(74)$ & $22(52)$ \\
Paradox & $50(66)$ & $24(71)$ & $26(62)$ \\
Arterial blood gas tensions & $47(62)$ & $19(56)$ & $28(67)$ \\
Inability to speak sentences & $53(70)$ & $28(82)$ & $25(60)$ \\
Serum potassium & & & \\
\hline
\end{tabular}

TABLE II - Emergency treatment definitely given within one hour after arrival at hospital by chest physicians and general physicians in 76 patients

\begin{tabular}{|c|c|c|c|}
\hline \multirow[b]{2}{*}{ Treatment } & \multicolumn{3}{|c|}{ No (\%) of case records } \\
\hline & $\begin{array}{l}\text { Overall } \\
(n=76)\end{array}$ & $\begin{array}{c}\text { Chest } \\
\text { physicians } \\
(\mathbf{n}=34)\end{array}$ & $\begin{array}{c}\text { General } \\
\text { physicians } \\
(\mathrm{n}=42)\end{array}$ \\
\hline Nebulised $\beta_{2}$ agonist & $60(79)$ & $30(88)$ & $30(71)$ \\
\hline $\begin{array}{l}\text { Intravenous hydrocortisone or oral } \\
\text { prednisolone }\end{array}$ & $43(57)$ & $24(71)^{\star}$ & $19(45)$ \\
\hline Nebulised ipratropium & $16(21)$ & $8(24)$ & $8(19)$ \\
\hline Theophylline or aminophylline & $9(12)$ & $5(15)$ & $4(10)$ \\
\hline
\end{tabular}

${ }^{\star} \chi^{2}=3 \cdot 9, \mathrm{df}=1 ; \mathrm{p}=0.047$, chest physicians versus general physicians. 
one hour from the time of arrival at hospital. Of the 76 patients, $60(79 \%)$ had received nebulised $\beta_{2}$ agonists within this period but only $43(57 \%)$ had received steroids. Chest physicians were more likely to give emergency treatment within the time and significantly more likely to do so for steroids $\left(\chi^{2}=3 \cdot 9, \mathrm{df}=1\right.$, $\mathrm{p}=0.05$; table II). The median time at which patients started steroids later than one hour after admission fell from 10 (range 2-166) hours in 1988-9 to $5 \cdot 5$ (range 2-10) hours in 1989-90.

Table III shows antibiotic prescribing. Forty five $(60 \%)$ of the patients were given antibiotics at some time during their inpatient stay, of whom $29(64 \%)$ met at least one of the criteria in the guidelines; there was no significant difference in antibiotic prescribing between chest physicians and general physicians. Sixteen (56\%) out of 28 patients in the 1988-9 sample who were given antibiotics met at least one criterion, compared with $13(76 \%)$ of 17 patients in the second sample, but the difference was not significant $(p=0 \cdot 3)$.

The guidelines recommend that steroid dosage be "tailored to response." This was difficult to assess as it was clear in only 31 of the 76 records (41\%) that patients' peak flow measurements had reached a plateau, and in only 27 (36\%) that "morning dips" in peak flow had ceased before the patient went home. Nevertheless, we could conclude that the guidelines were not adhered to in $47 \%$ of patients. For example, the audit highlighted one patient who was changed from nebulised treatment to inhaled treatment on day 3 and in whom steroids were first reduced on day 12 , yet whose peak flow reached a plateau on day 16 and ceased "dipping" in the morning on day 18 , the day before discharge. The chest physicians never reduced steroid treatment before changing from nebulised to inhaled treatment whereas the general physicians did this on six occasions.

Table IV shows the degree to which patients were referred to chest physicians, a requirement of the guidelines. Most (49/76, 64\%) patients admitted under the care of the general physicians were not referred for follow up at the outpatient chest clinic, and more of their patients were readmitted, including the two patients who had discharged themselves. The patient's ability to use an inhaler was recorded in only about a sixth of patients.

\section{Discussion}

For audit to be possible, accurate information must be available. Sampling and acquiring records posed many problems in this audit. Poor coding and the lack of linkage between information systems led to considerable extra work in identifying the medical record numbers and drawing an adequate sample. Some records could not be audited because vital documents were missing. Although we were able with persistence to draw an adequate sample to conduct the audit, the exercise highlighted yet again the need for better information systems if audit is to be carried out efficiently.

The design of the questionnaire was also crucial to the audit process, and our experience has implications for similar work by others. The questionnaire needed to focus on the most pertinent questions and be short, simple, and reliable enough to allow an audit assistant to extract accurate data from the patient record. The guidelines on which the questionnaire was based needed to be an acceptable summary of best current practice, which was confirmed by their concordance with those recently produced by the British Thoracic Society. ${ }^{8}$ The relative merits of our guidelines, however, were their brevity and the ease with which they could be rendered into questionnaire form. Our experience with guidelines produced within the
TABLE III - Antibiotic use and criteria for treatment by chest physicians and general physicians in 75 patients

\begin{tabular}{|c|c|c|c|c|c|}
\hline & \multicolumn{5}{|c|}{ No (\%) of case records } \\
\hline & $\begin{array}{l}\text { Overal } \\
(n=75)\end{array}$ & $\begin{array}{r}\text { Ch } \\
\text { physi } \\
(\mathrm{n}=\end{array}$ & $\begin{array}{l}\text { est } \\
\text { icians } \\
=33 \text { ) }\end{array}$ & $\begin{array}{r}\text { Ger } \\
\text { phys } \\
(\mathbf{n}=\end{array}$ & $\begin{array}{l}\text { eeral } \\
\text { icians } \\
=42 \text { ) }\end{array}$ \\
\hline Antibiotics given & \multicolumn{2}{|c|}{$45(60)$} & \multicolumn{2}{|l|}{$14(42)$} & \multirow[t]{3}{*}{$31(74)$} \\
\hline No criteria met & $16(36)$ & $5(36)$ & \multirow{2}{*}{\multicolumn{2}{|c|}{$\begin{array}{l}11(35) \\
20(65)\end{array}$}} & \\
\hline Criteria met & $29(64)$ & $9(64)$ & & & \\
\hline No antibiotics given & \multicolumn{2}{|c|}{$30(40)$} & $19(58)$ & & \multirow{3}{*}{$11(26)$} \\
\hline No criteria met & $20(67)$ & $12(63)$ & & $8(73)$ & \\
\hline Criteria met & $10(33)$ & $7(37)$ & & $3(27)$ & \\
\hline
\end{tabular}

*Data not available for one patient.

TABLE IV - Follow up patterns, and recording of inhaler technique by chest physicians and general physicians in 76 patients

\begin{tabular}{lrcc}
\hline & \multicolumn{3}{c}{ No (\%) of case records } \\
\cline { 2 - 4 } & $\begin{array}{c}\text { Overall } \\
(\mathbf{n}=76)\end{array}$ & $\begin{array}{c}\text { Chest } \\
\text { physicians } \\
(\mathbf{n}=34)\end{array}$ & $\begin{array}{c}\text { General } \\
\text { physicians } \\
(\mathbf{n}=42)\end{array}$ \\
\hline $\begin{array}{l}\text { Followed up in chest clinic } \\
\text { Readmissions for asthma within } \\
\text { three months }\end{array}$ & $49(64)$ & 34 & $15(36)$ \\
Recording of inhaler technique & $8(11)$ & $2(6)$ & $6(14)$ \\
\hline
\end{tabular}

hospital for other conditions is not always proving to be so straightforward. Much depends on the clarity and format of the guidelines. Moreover, the development, implementation, and subsequent analysis of the questionnaire required the combined skills of both the specialist physician and the experienced audit workers, which is not yet widely available. ${ }^{9}$ Finally, as in all such developmental work, our experience of using the questionnaire has led us to modify it for future use, but it has nevertheless proved an efficient instrument, which showed with a fairly small sample size the local existence of shortcomings in the management of asthma similar to those reported in larger studies elsewhere..$^{5 \cdot 7}$

Measurements of peak flow rates and pulse rates, which at this hospital are recorded by nurses, were better recorded than in previous studies. ${ }^{5}$ We found that the admitting doctors were poor at recording the severity of the asthma: general physicians did so in $60 \%$ of the admissions and chest physicians in $67 \%$. After the general introduction of audit in the hospital some improvement occurred but only the measurement of arterial blood gas tensions improved significantly. Serum potassium concentration was recorded in only $70 \%$ of patients. Yet hypokalaemia, which was found in a fifth of those patients, is thought to contribute to the occurrence of arrhythmias associated both with chronic airflow limitation and with many of the drugs used in managing asthma. ${ }^{10}$ Despite evidence that delayed treatment may be an important contributor to deaths from asthma ${ }^{2}$ there was still a delay in emergency treatment with steroids and $\beta_{2}$ agonists. The delay was less after the introduction of audit, and again the chest physicians' admitting team were more likely to give steroids early. Antibiotics were still overused compared with the hospital guidelines (and now the British Thoracic Society guidelines ${ }^{8}$ ), which suggests that physicians continue to believe that bacterial infection is a major component of asthma. ${ }^{\text {" }}$

Previous studies have shown reduced morbidity in patients admitted under the care of respiratory physicians compared with those admitted under the care of general physicians. ${ }^{7}$ The readmission rates in our audit were consistent with this finding, although the numbers are too small to draw firm conclusions. Nevertheless, it is widely acknowledged that all patients admitted with acute asthma should be referred to chest physicians, and the low referral rate is disappointing.

The audit findings were presented in full at a 
meeting attended by about 50 physicians of all grades, who concluded that the standards of care needed considerable improvement. It emerged that the guidelines were not widely used by the junior medical staff, and it was agreed that there should be a major effort to comply with the guidelines whenever possible and that a further audit should be carried out in one vear to assess whether this had been achieved. The resolve to improve the referral rate to the respiratory firm was reaffirmed at a subsequent joint meeting with some 40 local general practitioners who, after receiving the results confirmed that they would expect all asthmatic inpatients to be seen by a chest physician during their stay and for their outpatient follow up.

Our findings suggest that though the introduction of audit may have improved such processes as clerking and record keeping, ${ }^{1}$ it has resulted in relatively little specific improvement in clinical care. However, the use of a simple questionnaire which may be reliably used by an audit assistant has allowed us to follow the audit cycle for patients admitted with asthma, and we are now using the same methods to perform smaller and shorter studies for several other conditions, including some audits performed as medical student projects. Such audits commonly disclose that the guidelines and questionnaires themselves need substantial modification, and it is important, especially as there is likely to be a bias against the publication of failed audits, that the many groups of physicians in the
United Kingdom who are optimistically adopting similar methods are aware that useful audit results such as those presented here are not always as straightforward to achieve.

We thank Ms Jane Wadsworth for her statistical advice, and Dr Martin McNicol for his encouragement and help.

I Gabbay J, MCNicol MC, Spiby J, Davies SC, Layton AJ. What did audit achieve? Lessons from a preliminary evaluation of a year's medical audit. B.MF 1990;301:526-9

2 British Thoracic Association. Death from asthma in two regions of England. B.M. 1982;285:1251-5.

3 North West Thames Regional Health Authority. Standard mortality rates for arcuilable cases of death by district. Annual report on the health of the population-district tables 1988. London: North West Thames Regional Information Unit, 1989.

4 Averv $\mathrm{CH}$, March J, Brook RH. An assessment of the adequacy of self care by adult asthmatics. Fournal of Community Medicine 1980;5:167-80.

5 Reed S, Diggle S, Cushley MJ, Sleet RA, Tattersfield AE. Assessment and management of asthma in an accident and emergency department. Thorax 1985:40:897-902.

6 Rebuck AS, Read J. Assessment and management of severe asthma. Am $\mathcal{F}$ Med 1971;15:788-98.

7 Bucknall CF Moran F, Robertson C Stevenson RD. Differences in hospital asthma management. Lancet 1988; $1: 748-50$.

8 British Thoracic Society. Guidelines for management of asthma in adults: II acute severe asthma. B.MF 1990:301:797-800

9 Layton AJ. Making the most of audit workers. Health Service fournal $1990 ; 100: 1685$

10 Higgins RM, Cookson WOCM, Lane DJ, John SM, McCarthy GL, McCarthy ST. Cardiac arrhythmias caused by nebulised beta-agonist therapy. Lance $1987 ;$ ii: $863-4$

11 (jrant IWB. Guidelines for management of asthma. BMF 1990;301:1045.

Arcadia revisited: quality assurance in hospitals in The Netherlands

\section{Evert Reerink}

Of all the attributes of medical care the assurance of its quality is the least known. At best it is respected, but it is never loved and never popular. Scientific progress, medical research, eradication of disease, and alleviation of grief and sorrow continue to be the pinnacles of medical care. Accountability, openness, and empathy do not score highly. Yet these are equally traditional values of the medical profession that must be taught, disseminated, and, often, defended.

Medicine as it is practised is as much engrained in a country's culture and tradition as are, say, literature and the arts. If the intellectual and political climates are favourable to, or at least tolerant of, the development of arts and sciences, medical care will profit - and this holds true for quality assurance. The keys to the proper development of modern quality assurance are tolerance, common consent, and confidence. Conflict, mistrust, and competition are definitely counterproductive. Each country has the quality assurance system that befits its health care system.

\section{Dutch health care system}

In The Netherlands it seemed appropriate to hold physicians responsible for their professional work, and on this basis they claimed responsibility for the quality of their care, the ultimate consequence of which is to assess quality and, if necessary, improve it. Assessing and improving quality is relatively recent. In the 1960 s and early 1970s few professionals bothered. Around 1975, however, hospital doctors, united in their national specialists organisation, Landelijke Specialisten Vereniging, and perhaps triggered by the developments in the USA, where state organisations
(Professional Standards Review Organizations) had been established to look into the quality of medical care in hospitals, and by the realisation that the current methods of quality care assurance were hopelessly outdated, renewed the tenet that physicians must be responsible for their quality of work. The Landelijke Specialisten Vereniging also took the next step: though professing their responsibility, specialists also acknowledged their ignorance of how to conduct modern quality assurance. Help and support were necessary. ${ }^{1}$ The government fell in with the idea for this initiative, leaving professional quality assurance to the health professions and supporting the creation of $\mathrm{CBO}$, an organisation to help clinicians in their self imposed task of quality assurance. The government completed the so called tripod of quality assurance by declaring openly its non-interference in quality assurance in the health care sector and instead professed its commitment to the cause. It and subsequent governments were set on a course of diminished interference in health care, and the new proposal fell on fertile ground. However, all parties thought that something should be done about the perceived unattained benefit in medical care.

\section{Present problems in health care}

At that time the Dutch health care system, which had previously been in good shape, started to show several shortcomings. This was not unique: the health care system in The Netherlands had (and has) similar problems to those of health care systems in other developed countries. There is considerable similarity between the health care problems in The Netherlands 